\title{
Los cuatro estratos de Roman Ingarden como fundamento teórico para el análisis de las traducciones literarias
}

\section{(Roman Ingarden's Four Strata as a Theoretical Basis for the Analysis of Literary Translations)}

\author{
AlfREdo HeRmosillo López \\ ahermosillo2175@gmail.com \\ Universidad de Guadalajara
}

Fecha de recepción: 28 de marzo de 2016

Fecha de aceptación: 9 de mayo de 2016

Resumen: Este artículo analiza la teoría de los cuatro estratos del filósofo polaco Roman Ingarden. Tiene el propósito de mostrar que sus conceptos sobre la lectura activa y la obra de arte literaria, además de ser el punto de partida de los estudios de recepción desarrollados más ampliamente por Hans-Robert Jauss y Wolfgang Iser, pueden utilizarse como fundamento teórico para el análisis de traducciones literarias.

Palabras clave: Concretización, Traducción fidedigna, Lector esteta, Cuatro estratos.

Abstract: This article analyses the theory of the four strata proposed by the Polish philosopher Roman Ingarden. Its main purpose is to show that Ingarden's concepts regarding the active reading and the literary work of art, besides from being the starting point of the literary reception studies, developed more widely by Hans-Robert Jauss and Wolfgang Iser, can also be used as a theoretical foundation for the analysis of literary translations.

Key words: Concretization, Reliable translation, Esthete reader, Four strata.

INTRODUCCIÓN

El filósofo polaco Roman Ingarden, discípulo avanzado de Edmund Husserl y fundador de la neo-hermenéutica, publicó dos obras fundamentales: 
La obra de arte literaria (1931) y La comprehensión de la obra de arte literaria (1937). Ambos libros aparecieron en inglés en 1973 y fueron traducidos al español en 1998 y 2005, respectivamente, por Gerald Nyenhuis. En su primera obra, Ingarden llega a la conclusión de que la obra de arte literaria está formada por cuatro estratos: a) Palabras-sonidos. b) Unidades con significado. c) Objetos representados. d) Aspectos esquematizados. De la materia y la forma de cada estrato resulta una conexión interior de todos los estratos, lo cual constituye la unidad formal de la obra.

En el segundo libro, Ingarden se dedica al estudio de la interrelación entre la obra y sus concretizaciones, es decir, de los procesos que conducen al lector a la comprensión de una obra de arte literaria. Al afirmar que los cuatro estratos forman una estructura esquemática o esqueleto que debe ser completado por el lector, Ingarden fija el punto de partida para los postulados de Hans-Robert Jauss y Wolfgang Iser. Descubre que los objetos representados en la obra exhiben puntos de indeterminación que son llenados por el lector mediante el proceso cognitivo que llamó concretización, en el que lector incorpora su subjetividad y valores en el rellenado del esquema:

En la obra misma están presentes solamente aspectos esquematizados - ciertos esquemas que permanecen como estructuras constantes por medio de las diversas modificaciones de percepción. Tan pronto como sean actualizados por el lector, se hacen concretos por sí mismos. Son aumentados y complementados datos concretos, y la manera en que esto ocurre depende en gran medida del lector. Éste llena el esquema general de aspectos con los detalles que corresponden a su sensibilidad, sus hábitos de percepción y su preferencia por ciertas cualidades y por ciertas relaciones cualitativas; estos detalles varían, y pueden diferir, de lector a lector (Ingarden, 1998: 80).

Es importante destacar que Ingarden no limita la obra literaria a la experiencia psíquica de los lectores, pues su existencia no depende únicamente de ellos, sino de la interrelación entre el lector y el texto. Así pues, toda interpretación debe estar limitada por las estructuras textuales.

\section{EL TRADUCTOR COMO LECTOR ESTETA}

La fortuna de una obra literaria depende, en buena medida, de la imagen que crea la crítica. El traductor es el primer crítico de una obra, pues para dar nueva vida a un texto tiene que elegirlo, decidir qué clase de vida le otorgará, y cómo los introducirá en la cultura receptora. Por otra parte, la tarea de un 
traductor no es la de sustituir palabras de una obra literaria por diferentes sonidos tomados de otro lenguaje. No se traduce una palabra sino unidades de lenguaje (con palabras y sintaxis diferentes al original).

Siguiendo estas nociones, puede decirse que el traductor es un lector creativo que se adentra en el texto y se compromete con él. Es, por lo tanto, primero un lector que "concretiza" la obra (llena, completa sus espacios de indeterminación, sus ambigüedades); luego un crítico literario que decide qué y cómo traducir, creando así la imagen del texto de origen que presentará en la cultura de acogida; finalmente, un creador que reescribe su lectura en otra lengua, ya que una vez comprendida la obra, aún queda la tarea de reescribirla. Para Ingarden, una tarea tan compleja sólo puede ser realizada adecuadamente por un lector esteta:

[ ...] hay un tipo especial de la obra de arte literaria cuyo carácter básico y cuyo encanto peculiar descansa en las ambigüedades que contiene. Su presencia es una presencia calculada para el pleno deleite de los caracteres estéticos que se basan en la "iridiscencia" y la "opalescencia" que perderían su encanto si alguien quisiera mejorar la obra evitando las ambigüedades (como, por ejemplo, pasa con frecuencia en las malas traducciones) (Ingarden, 2005: 170).

La afirmación de Roman Ingarden, quien considera al lector-críticotraductor esteta como idóneo para lograr una buena traducción, es fundamental para el análisis de las traducciones, ya que si el traductor está "distraído" por consideraciones políticas, religiosas, morales, etcétera, o apremiado por compromisos con su editorial, difícilmente llevará a cabo una traducción fidedigna que rescate los valores estéticos esenciales a la obra de arte literaria.

Siguiendo las ideas de Ingarden, resulta evidente que en el análisis de las traducciones debe prestarse particular atención a la figura del traductor como ente histórico, pues aunque ha sido olvidado en muchas ocasiones, es indudable su influencia en el texto. Visto así, el estudio de las traducciones requiere una breve biografía del traductor, en la que se describa su relación con las culturas de origen y de acogida, y se explique si es profesional de la traducción, escritor u otro caso. Conocer tanto la trayectoria del traductor como sus gustos literarios y otras actividades intelectuales que realizó, puede orientarnos sobre la práctica traductora y los principios que lo guiaron. También permite comprender cómo han determinado la traducción los discursos sociales, ideológicos y estéticos de su época. 
Roman Ingarden nos demuestra, pues, que es necesario situar a cada traductor en el contexto que le corresponde. No podemos soslayar que es un ser histórico que llega a la obra en una época determinada y que traduce para unos lectores que también son históricos. Por lo tanto, ambas figuras están determinadas por factores temporales (cultura, gustos estéticos, censura, ideas políticas, criterios editoriales vigentes en la época, etcétera) que influyen en la manera de traducir:

\begin{abstract}
Es sabido que cada época en el desarrollo general de la cultura humana tiene su propio entendimiento, su propio tipo de valores estéticos y no estéticos, su propia predisposición a una y no a otra manera de aprehender el mundo en general y las otras obras de arte en particular. En algunas épocas tenemos una susceptibilidad especial hacia unas cualidades de valores estéticos mientras que permanecemos ciegos a otras. Las concretizaciones de la obra literaria dependen de las actitudes del lector y por consecuencia están marcadas en varios aspectos por los "rasgos de los tiempos" (Ingarden, 2005: 405).
\end{abstract}

En resumen, Ingarden nos invita a abordar el estudio de las traducciones de una manera global, considerando sus diversos factores, pues el largo camino recorrido por una obra traducida hasta llegar al lector está determinado por cuatro momentos clave: en primer lugar, la circunstancia histórico-política o cultural que la hace interesante o no para su traducción y publicación; en segundo, las decisiones de los editores a la hora de traducir y publicar una obra y no otra, establecidas normalmente por razones de mercado y no de calidad; un tercer momento está marcado por las políticas de las librerías y de las bibliotecas; finalmente, el trabajo de los críticos, quienes determinan en buena medida la recepción de una obra por parte del público lector.

\title{
2. TRADUCCIÓN FIDEDIGNA
}

Existe un enfrentamiento entre quienes piensan que traducir es recuperar la intención del autor reducida a un solo significado, y los que piensan que es buscar significados al infinito, en un ejercicio que no termina. Tenemos, por un lado, la traducción literal que es una mera sustitución de vocablos de una lengua a otra, palabra por palabra según las posturas más radicales, respetando la sintaxis de la lengua original. Podemos identificar el concepto de traducción literal con el de traducción fiel: La sustitución de sonidos (palabras) de una obra literaria por diferentes sonidos tomados de otro lenguaje. Entendido 
así, el traductor es un mal necesario que se interpone entre el tesoro del texto original y la ignorancia del lector.

Los que apuestan por la traducción literal sostienen que el traductor debe propiciar el encuentro con un autor extranjero siendo fiel al estilo de la lengua original, por muy desaliñada o extraña que pueda resultar en la lengua de acogida. Afirman que el lector no debe olvidar que se enfrenta a una obra ajena a su idioma. Por lo tanto, la "agramaticalidad" conseguida es un logro.

Revisemos el segundo modo de traducir, el modelo funcionalista al que no le preocupa la fidelidad al texto de origen. Esta teoría agrupa distintos enfoques que consideran la traducción como una actividad determinada por el fin que persigue (Reiss \& Vermer, 1996). El postulado fundamental de la teoría funcionalista de la traducción es el destronamiento del texto de origen, al que consideran únicamente como una de las muchas fuentes de información con las que cuenta el traductor. Para estos teóricos el factor decisivo al evaluar el trabajo de traducción es su aceptabilidad en la cultura meta. El receptor, pues, tiene la última palabra, dejando al texto de origen en un segundo plano.

Por ejemplo, si el propósito general del traductor es ganarse la vida y para este fin debe atenerse a las reglas fijadas por la línea editorial, puede atribuirse el derecho de adaptar el estilo (limar rarezas, metáforas incomprensibles, juegos de lenguaje, descripciones exhaustivas...) de un escritor de difícil lectura para el público al que se dirige. Si, por otra parte, se tiene como propósito escribir un manual para la enseñanza de una lengua extranjera, puede apegarse a la traducción palabra por palabra para mostrar las características del idioma que se pretende enseñar.

La tensión descrita entre quienes piensan que interpretar es recuperar el significado intencional del autor reducido a un significado unívoco y los que aseguran que es buscar significados al infinito, nos enfrenta a una falsa dicotomía, pues no son estos dos caminos distantes los únicos que podemos transitar. Si bien toda traducción es producto de una interpretación del texto de origen, pueden establecerse filtros que impidan la arbitrariedad del traductor en el desempeño de su tarea. Entre el significado unívoco del texto y la lectura equívoca que nos permite utilizar el texto de cualquier manera, existe una teoría de la interpretación centrada en el código textual y en los procesos de lectura.

¿Qué argumentos opone Roman Ingarden a estas dos maneras de entender la traducción? Al distinguir entre traducción fiel y traducción fidedigna Ingarden nos proporciona un argumento sólido contra la traducción literal. La tarea de un traductor no es la de sustituir palabras de una obra literaria por diferentes sonidos tomados de otro lenguaje. Tampoco se adscribe al modelo 
funcionalista de la traducción, pues establece filtros a la libre utilización del texto y no acepta que cualquier lectura es válida, pues esta depende del esquema proporcionado por la obra. Es decir, se distancia de una teoría del uso para situarse en una teoría de la interpretación de textos. Para Ingarden, la libertad de interpretaciones está limitada al código textual, está inscrita en el propio mecanismo del texto y es una condición inexcusable del mismo.

Al concepto de Traducción fiel (literal) Ingarden opone el de Traducción fidedigna, que se consigue cuando el traductor "descifra" el texto en una forma "adecuada al sentido", para que la obra reaparezca en su propia forma sin "falsificaciones" y "malentendidos". Tenemos, entonces, que una traducción es fidedigna cuando el significado y la intencionalidad del autor del texto de origen no son alterados de forma significativa. ¿Cómo saber si el texto traducido ha sido o no alterado de forma significativa? Un análisis de traducción basado en la teoría de los cuatro estratos puede dar la respuesta.

\section{LOS CUATRO ESTRATOS COMO FUNDAMENTO PARA EL ANÁLISIS DE LAS TRADUCCIONES \\ Según Ingarden, de la materia y la forma de cada uno de los cuatro estratos resulta una conexión interior que constituye la unidad formal de la obra. Seguidamente, analizaré cada uno de ellos:}

\section{LOS CUATRO ESTRATOS:}

\subsection{Palabras-sonidos:}

Enriquecen la totalidad de la obra por una materia singularmente formada y por un valor estético particular que constituyen, junto con las cualidades de valor que brotan de los demás estratos de la obra, la polifonía peculiar de la obra literaria (Ingarden, 2005: 76).

Pertenecen a este primer estrato lo que Ingarden llamó fenómenos fónicos:

(1) Ritmo: "descansa sobre la repetición de determinadas secuencias de sonidos acentuados y no acentuados". (Ingarden, 2005: 69). 
(2) Tempo:

Una característica determinada del lado fónico del lenguaje, su agilidad o su lentitud, su ligereza o su floja pesadez. Esta característica es condicionada por las propiedades del ritmo inmanente en el texto y es producido por la velocidad que le es peculiar a él y dictada por él (Ingarden, 2005: 69-70).

(3) Melodía (s) de la obra literaria:

[...] son condicionadas y constituidas sobre todo por la presencia de los sonidos verbales, de una sucesión de vocales con un tono específico [...] cada lengua viva y en un grado mayor, un dialecto tiene sus propiedades melódicas características. (Ingarden, 2005: 71).

El ritmo, el tempo y la melodía no pueden conservarse íntegramente en una traducción, por muy fidedigna que esta se pretenda, pues al trasladar los sonidos de un idioma a otro las modificaciones resultan inevitables. El texto traducido presentará, invariablemente, diferencias considerables respecto al original.

En algunos casos, la imposibilidad de una traducción adecuada del estrato fonético altera de tal modo el ritmo de una obra que "puede contrariar la esencia de este estrato a tal grado que los demás estratos no puedan alcanzar su debida expresión en una lectura dada" (Ingarden, 2005: 69), perdemos, entonces, la polifonía general de la obra; su significado se nos ha escapado para siempre. Estos aspectos son especialmente pertinentes al traducir, por ejemplo, del ruso al español, ya que son lenguas musicalmente muy distintas. El caso de Gógol es ilustrativo, pues los efectos acústicos de Almas muertas, por ejemplo, resultan imposibles de trasladar en traducción. La riqueza de la prosa gogoliana depende en buena medida de su musicalidad, lograda por una peculiar combinación de sonidos que resulta evidente desde el inicio de la novela: красивая рессорная небольшая бричка (krasívaia, resórnaia ne bolshaia brichka). Otro ejemplo es la frase: день был не то ясный, не то мрачный (dien bil nie to yázni, nie to mráchni), que se traduce al español como "el día no era ni claro ni nublado". En ruso, el atractivo de estas frases reside en su precisión y la sonoridad. Las traducciones al español no logran transmitir la musicalidad distintiva del texto en ruso.

Al sustituir palabras-sonidos de un idioma por palabras-sonidos de otro el texto de origen y el texto meta presentarán diferencias considerables y el 
significado variará. Sin embargo, la dificultad de la tarea no debe impedir que un traductor intente conservar en lo posible el ritmo del original, identificando mediante una lectura atenta y una correcta interpretación su tempo (agilidad, lentitud, ligereza, o floja pesadez). De los tres fenómenos fónicos comentados por Ingarden, el traductor debe estar pendiente del ritmo y el tempo, pues la melodía, al pertenecer específicamente a una lengua en particular, de cualquier modo se le escapará.

\subsection{Unidades semánticas o de sentido:}

La unidad de sentido puede estar formada por una sola palabra o por frases o párrafos enteros. La unidad de sentido es la oración (o complejo de oraciones), definida por Ingarden como:

[...] una unidad de sentido intencional/funcional que se construye como una totalidad auto-suficiente. Los sentidos verbales entran en ella como componentes, sin embargo, no es ella una suma o un agregado de sentidos verbales; más bien es una nueva objetividad [...] en ocasiones, la intencionalidad de la unidad de sentido puede ser ambigua (Ingarden, 2005: 131).

La obra cambia en manos del lector, puede ser cambiada o hasta destruida por operaciones subjetivas, por las distintas concretizaciones de sus lectores. La obra puede ser alterada por el traductor (que es, antes que todo, un lector de la obra) con intención consciente si éste establece una conexión distinta entre las oraciones o incluso introduce algunas nuevas. El traductor también puede, sin proponérselo, modificar sustancialmente la obra mediante una concretización equívoca. La traición puede darse a pesar de las buenas intenciones del lector/traductor, por ejemplo, cuando:

[...] absolutiza una concretización dada y la identifica con la obra y de una manera genuina se dirige intencionalmente a la obra así intencionada. Todo lo que pertenece al contenido de una concretización dada es entonces atribuido a la obra (Ingarden, 2005: 411).

El lector en este caso no es consciente de lo fortuito de una concretización y de que ésta difiere del texto de origen. "No se analiza la obra con cuidado en una actitud crítica y con una receptividad precavida para quitar todas las impurezas, sino, más bien, es violada y alterada" (Ingarden, 2005: 411). 
Los objetos representados en la obra tienen puntos de indeterminación que el lector completa incorporando vivencias y valores en el rellenado del esquema que ofrece la obra. A este papel activo de la lectura, decíamos, Ingarden llamó concretización. Sin embargo, las concretizaciones no se limitan a una mera subjetividad, no cualquier lectura es válida pues ésta depende del esquema proporcionado por el texto. La tarea del traductor es fundamentalmente subjetiva, pero todo buen traductor debería aceptar que su interpretación está limitada por el marco textual.

\subsection{Objetos representados:}

Los objetos representados son elementos constitutivos de la obra, correlatos intencionales de las oraciones que hay que diferenciar de los objetos reales autónomos a ella. En contraste con los objetos reales u objetivos, que son universales, inequívocos y determinados, los objetos representados son solamente una formación esquemática con puntos de indeterminación que el lector deberá completar con su lectura.

Con el fin de eliminar posibles malentendidos, Ingarden hace hincapié en que la expresión "objetos representados" debe entenderse en un sentido amplio: se refiere tanto a cosas como a personas, pero también a acontecimientos, ocurrencias, estados, actos realizados por las personas, etcétera. En una traducción fidedigna, todos los objetos representados en el texto original deben incluirse en el texto meta.

En ocasiones, los traductores deciden pulir y normalizar el texto, simplificando, por ejemplo, la estructura de los párrafos, el estilo reiterativo y las frases coloquiales o vulgares, lo que ocasiona una considerable pérdida de la expresividad respecto del original y, por lo tanto, una traducción no fidedigna, ya que omiten unidades de sentido y objetos representados. El siguiente fragmento, tomado de una traducción al español de Almas muertas de N.V. Gógol, es una muestra de ello:

Поодаль, в стороне, темнел каким-то скучно-синеватым цветом сосновый лес. Даже самаяпогода весьма кстати прислужилась: день был не то ясный, не то мрачный, а какого-то светло-серого цвета, какой бывает только на старых мундирах гарнизонных солдат, этого, впрочем, мирного войска, но отчасти нетрезвого по воскресным дням (Gógol, 2008: 23).

A lo lejos veíase la sombra de insípido color azulado de un bosque de pinos. También el cielo estaba en armonía con el aspecto general del 
paisaje: no era claro ni oscuro, sino que tenía un matiz gris pálido que sólo es posible hallar en los viejos uniformes de los soldados de guarnición (Gógol, 1944: 29).

Un poco más lejos se veía la sombra azulada de un desvaído pinar. Incluso el tiempo se había puesto a tono con el paisaje, pues el día no era ni claro ni nublado, sino de ese peculiar color azul grisáceo que se ve únicamente en los viejos uniformes de los soldados de guarnición, tropa por lo demás pacífica, si bien algo bebida los domingos (Gógol, 2015: 105)

En el primer fragmento en español, no se traduce la conexión entre el cielo grisáceo y el uniforme de los soldados de una tropa, dos términos que, unidos, debieron parecerle al traductor un despropósito. Seguramente, el hecho de que la tropa bebiera los domingos le resultó irrelevante. Sin embargo, estos detalles son fundamentales en el estilo gogoliano; por lo tanto, no pueden ser eliminados en una traducción.

\subsection{Aspectos esquematizados por los cuales estos objetos aparecen:}

Los aspectos esquematizados son la punta de un iceberg. Constituyen el esqueleto de la obra que el lector completará. Si ponemos en relación los estratos 3 (cosas, gente, procesos, acontecimientos...) y 4, podemos decir que el escritor dota a los objetos representados en su obra con propiedades que provocan una respuesta en el lector, este es el aspecto con que presenta su objeto. El autor debe ocultar que estos objetos representados son imaginarios, lo logra mediante la inclusión de aspectos esquematizados que convencen al lector de su verosimilitud y lo ayudan a concretizarlo en su mente. Vemos una parte de la realidad del objeto, completamos el esquema basándonos en la parte oculta del iceberg.

Los esquemata, como los llama Ingarden, permiten identificar la totalidad de un objeto mediante la observación de uno de sus aspectos. Al ver por primera vez un samovar, por ejemplo, nos formamos un esquema mental de este objeto que nos permitirá identificarlo cuando lo encontremos en la lectura. La formación de los esquemata parte de la experiencia, por lo tanto, es evidente que no podemos completar un esquema de un objeto que nunca hemos experimentado. En tal caso, se nos escapa la intencionalidad del autor. El lector puede, ante un aspecto esquematizado que desconoce, identificarlo equivocadamente; así pues, el traductor debe estar atento: Cuando considere que los objetos del texto de origen son poco conocidos para los lectores del texto meta, deberá modificar de algún modo el texto (y aquí el destino de la 
traducción queda en manos de su intuición artística). O puede, si las características de la edición lo permiten, añadir información mediante notas.

El siguiente ejemplo muestra que en ocasiones el traductor se ve obligado a recurrir a notas al pie para explicar los juegos de palabras, pues aunque son comprendidos directamente por un lector ruso, son imposibles de pasar al español. Explico el contexto: En Almas muertas, el narrador subraya la similitud de Sobakévich con un oso de tamaño regular, que para colmo se llama Mijaíl Semiónovich. Las traducciones que he revisado añaden la siguiente información:

1. Traducción de R. Slaby: "Nombre popular del oso, en Rusia" (Gógol, 1926: 110).

2. Traducción de J. Laín Entralgo: "Los rusos llaman Misha o Mishka, diminutivo familiar de Mijaíl, a los osos" (Gógol, 2008: 82);

3. Traducción de A. Vidal: "En Rusia a los osos se les da el nombre de Misha o Mishka, diminutivo familiar de Mijaíl" (Gógol, 1998: 124).

La tarea del traductor es a veces ingrata, ya que no existe garantía absoluta de la fidelidad de la reconstrucción de la obra. Sin embargo una cuidadosa atención a los estratos fonético y semántico puede eliminar los errores más graves en la reconstrucción.

\section{CONCLUSIONES}

El análisis fenomenológico de la obra de arte literaria, que sentó las bases para la estética de la recepción y la neohermeneútica, enuncia conceptos que pueden utilizarse con fundamento teórico para los estudios de traducción. He mostrado que, entendido a partir de Ingarden, el análisis de las traducciones literarias debe incluir al estudio de la interrelación entre la obra de origen y sus concretizaciones en la lengua meta. Esto significa, por ejemplo, que el examen de las diversas traducciones de Almas muertas de N.V Gógol, debe tener en cuenta la figura de cada traductor como ente histórico, para situarlo en el contexto que le corresponde. Este conocimiento del traductor permitirá comprender cómo percibe su tarea, con qué estrategias aborda los textos de origen y de llegada, que ideas preconcebidas tiene de su labor y de la obra que traduce, qué usos léxicos y sintácticos prefiere... Aspectos, pues, sin duda marcados por el discurso social e ideológico de su tiempo. Esto, que parece una obviedad, ha sido constantemente olvidado en los análisis traductológicos.

En este proceso dialógico, el sentido de una obra está siempre abierto a nuevas interpretaciones, actualizadas de recepción en recepción, pues un texto es un conjunto de signos que producen sentido y es, también, un objeto 
susceptible de modificaciones y manipulaciones a través del tiempo. Por ello, Ingarden no pretende que la traducción sea fiel, sino fidedigna. Esto puede lograrlo el traductor cuando se sitúa en un camino intermedio entre las teorías literal y funcionalista de la traducción. Y también si centra su interpretación en el código textual. Así pues, un análisis comparativo de las diferentes versiones de un mismo texto de origen puede revelar qué tipo de estrategia siguió cada traductor, y qué tan fidedignos son sus resultados.

Por otra parte, la teoría de los cuatro estratos permite un análisis comparativo más detallado, en el que pueden examinarse fragmentos de traducciones, detenida y minuciosamente, a partir de cada uno de los apartados propuestos por Roman Ingarden. En este artículo he propuesto algunos ejemplos para mostrar la manera en que puede realizarse el análisis. Cabe decir, por supuesto, que el estudio de las traducciones debe abordarse desde una perspectiva más global y exegética. Es decir, tiene que intentar explicar las divergencias entra las traducciones y el original a partir de su contexto histórico, pues un análisis de traducción no debe limitarse a elaboración de un catálogo de "errores" o divergencias.

Finalmente, rescato una idea de Ingarden que me parece fundamental: la afirmación de que una tarea tan compleja como la traducción literaria sólo puede abordarla adecuadamente un lector esteta que se comprometa con los valores artísticos del texto de origen, y que intente trasladarlos al de llegada como lo haría un escritor de textos "originales". Esto es, que considere la traducción como una forma de creación artística.

REFERENCIAS BIBLIOGRÁFICAS

GóGOL, Nikolái, Almas muertas: aventuras de Chíchikov. Barcelona: Cervantes, 1926.

—, Almas muertas. Barcelona: Joaquín Gil, 1944.

—, Almas muertas. Barcelona: BackList, 2008.

-, Almas muertas, El capote, y otros relatos. Barcelona: Círculo de Lectores, 1991.

—, Almas muertas. Madrid: Cátedra, 2015.

INGARDEN, Roman, La comprehensión de la obra de arte literaria. México: Iberoamericana, 1998.

—, La obra de arte literaria. México: Taurus/lberoamericana, 2005.

REISS, Katharina; Hans, Vermeer: Fundamentos para una teoría funcional de la traducción. Madrid: Akal, 1996.

Гоголь, Николай, Мертвые души. Москва: Дрофра, 2008.

Hikma 15 (2016), 41-52 